\title{
CONSEQUENCES OF THE PRICE DECREASE FOR PRESCRIPTION (RX) DRUGS 2015 - 2019
}

\author{
PETRU CRĂCIUN ${ }^{1 *}$, MARIAN PANĂ $^{1 *}$, ADRIANA-ELENA TĂEREL $^{2 \#}$, MANUELA GHICA $^{3 \#}$, \\ DUMITRU LUPULIASA $^{1}$ \\ IPharmaceutical Technology and Biopharmacy Department, Faculty of Pharmacy, "Carol Davila” University of Medicine \\ and Pharmacy, Bucharest, Romania \\ ${ }^{2}$ Department of Pharmaceutical Management and Marketing, Faculty of Pharmacy, "Carol Davila” University of Medicine \\ and Pharmacy, Bucharest, Romania \\ ${ }^{3}$ Department of Biostatistics, Faculty of Pharmacy, "Carol Davila” University of Medicine and Pharmacy, Bucharest, \\ Romania
}

*corresponding author: marianpana@ colegfarm.ro

${ }^{\#}$ Authors with equal contribution.

Manuscript received: August 2020

\begin{abstract}
The price regulation of July $1^{\text {st }}, 2015$, also known as "the smallest European price policy" was adopted in order to widen the access to drug treatment for patients in Romania, without a significant cost to public expenses. Within the analysed period (July 2015 - June 2019), this policy has had negative effects, somewhat contrary to the initially announced intentions. The increase in disparities in drug consumption between the large cities and the small towns (including the rural areas), the discrimination of generic drugs, the disappearance of a significant number of products and INNs, the establishment of socalled "in-deficit drugs", as well as the increase of the proportion of truly expensive drugs are all shortcomings of the current price policy and thus recommend the fundamental change of this policy. The main problems that continue to be unsolved (in a sustainable way) are: the prices for the Rx drugs of up to $50 \mathrm{RON}$ (which represent over $90 \%$ of the volume of current consumption) and the prices for Rx drugs of over $1.000 \mathrm{RON}$ (which represent the first segment of cost increase for drugs within the 4 analysed years).
\end{abstract}

\section{Rezumat}

Reglementarea prețurilor de la 1 iulie 2015, cunoscută şi ca „politica celui mai mic preț din Europa”, a fost adoptată cu motivația de a lărgi accesul pacienților din România la tratamentul cu medicamente fără o creștere semnificativă a cheltuielilor publice. În perioada analizată (iulie 2015 - iunie 2019), această politică a produs efecte negative și oarecum contrare intențiilor anunțate. Creșterea disparităților în asistența cu medicamente între orașele mari și orașele mici (inclusiv rural), discriminarea medicamentelor generice, dispariția unui număr semnificativ de produse şi DCI-uri, consacrarea „medicamentelor deficitare”, ca și creșterea ponderii medicamentelor cu adevărat scumpe reprezintă neajunsuri ale politicii de preț actuale și recomandă schimbarea în profunzime a acesteia. Problemele principale care rămân nerezolvate sustenabil sunt: prețurile pentru medicamentele Rx de până la 50 lei (care reprezintă peste $90 \%$ din volumul consumului actual) și prețurile pentru medicamentele Rx peste 1.000 lei (care reprezintă primul segment de creștere al cheltuielilor cu medicamente în cei 4 ani analizaţi).

Keywords: prescription drugs, innovators, generics, costs

\section{Introduction}

Medicines represents 20 - $60 \%$ of global health care spending, being the second "expenditure item after food", as "WHO guideline on country pharmaceutical pricing policies" said [25]. In the European Union pricing and reimbursement systems of pharmaceuticals are established mostly by National authorities, as long as "requirements of Directive $89 / 105 /$ EEC issued by the European Commission to ensure the transparency of national pricing and reimbursement regulations" are respected [9, 13, 22]. Studies have showed significant differences in drug prices in European countries [24]. There are many practices and policies used to control pharmaceutical expenditure $[4,23]$, some of them focused on drug-pricing measures that can be taken in order to reduce spending on medicines $[1,10]$. Being a European Union Member State, Romania has always adapted the laws and practices concerning the pricing of medicinal products existing at the EU level in order to address national demands [17-19]. In Romania the prices for prescribed medicines were established according to the provisions of Health Minister Order no.75/2009 for the approval of the Norms on the calculation module of prices for medicinal products for human use, published in the Official Gazette of Romania (part I, no.62 of February 2, 2009). After six years from the publication of Order $75 / 2009$, it was performed for the first time the annual review of drug prices, the result being an abrupt decrease 
between $16 \%$ and $25 \%$ of the drug prices regulated by the order [26]. A major challenge for Romanian health system was to allow better access to medicinal products and medical treatment, according to the "State of health in the EU: Country profile Romania 2017" [5].

Consequently, adopted on July $1^{\text {st }} 2015$, the administrative measure to reduce Rx drug prices (also adopted in Latvia and Poland) was met with hope by the Romanian patients, having been promoted as a way to ensure wide access to treatment, as well as avoiding significant public costs increases on this segment of the drug market $[2,24]$. However, the measure was taken without having performed an impact analysis and denotes an elementary ignorance (or intentional ignorance) of the way the market economy functions; in general, the forced reduction of prices without accounting for the supply-demand relationship leads eventually to a shortage. For instance, policies like price reduction had led to parallel trade (from low-price to high-price markets) among member countries of the European Union, resulting in drug shortages and lower access of new drugs. [3, 8, 11, 15]. Moreover, neither was this a administrative measure followed by an analysis of the produced effects and the current article is substituting for the actual fulfilment of this need by trying to unravel the important nuances after 4 years of applying "the policy of the smallest European price" to Rx drugs.

We will focus on the analysis of Rx drugs evolution within retail pharmacies because they represent the channel through which the vast majority of drug treatments are being released $(95.1 \%$ of the volume, $87.9 \%$ of the value and $98.0 \%$ of the duration of treatment).

Drug Consumption in the

\begin{tabular}{|l|c|c|c|c|c|c|c|c|c|}
\hline \multirow{2}{*}{ Segment } & \multicolumn{2}{|c|}{ Volume (Units) } & \multicolumn{2}{c|}{ PPP value } & \multicolumn{2}{c|}{ CPP Value } & \multicolumn{2}{c|}{ CPP Average Price } & \multicolumn{2}{c|}{ Days of treatment } \\
\cline { 2 - 10 } & mil. & $\%$ & mil. RON & $\%$ & mil. RON & $\%$ & RON & mil. & $\%$ \\
\hline Total & $\mathbf{5 4 3 . 0}$ & $\mathbf{1 0 0 \%}$ & $\mathbf{1 2 , 4 8 5 . 3}$ & $\mathbf{1 0 0 \%}$ & $\mathbf{1 3 , 7 3 1 . 7}$ & & $\mathbf{2 5 . 2 9}$ & $\mathbf{6 , 9 5 8 . 8}$ & $\mathbf{1 0 0 \%}$ \\
\hline Pharmacies & $\mathbf{5 1 6 . 6}$ & $\mathbf{9 5 . 1 \%}$ & $\mathbf{1 0 , 9 7 0 . 3}$ & $\mathbf{8 7 . 9 \%}$ & $\mathbf{1 3 , 7 3 1 . 7}$ & $\mathbf{1 0 0 \%}$ & $\mathbf{2 6 . 5 8}$ & $\mathbf{6 , 8 1 8 . 5}$ & $\mathbf{9 8 . 0 \%}$ \\
\hline OTC & 174.7 & $32.2 \%$ & $2,228.8$ & $17.9 \%$ & $2,871.9$ & $20.9 \%$ & 16.43 & 925.4 & $13.3 \%$ \\
\hline Rx & 341.8 & $63.0 \%$ & $8,741.5$ & $70.0 \%$ & $10,859.8$ & $79.1 \%$ & 31.77 & $5,893.1$ & $84.7 \%$ \\
\hline - Innovator $R x$ & 126.0 & $23.2 \%$ & $6,099.7$ & $48.9 \%$ & $7,407.1$ & $53.9 \%$ & 58.78 & $2,391.1$ & $34.4 \%$ \\
\hline - Generic Rx & 215.8 & $39.7 \%$ & $2,641.8$ & $21.2 \%$ & $3,452.7$ & $25.1 \%$ & 16.00 & $3,502.0$ & $50.3 \%$ \\
\hline Hospitals & $\mathbf{2 6 . 4}$ & $\mathbf{4 . 9 \%}$ & $\mathbf{1 , 5 1 5 . 1}$ & $\mathbf{1 2 . 1 \%}$ & $\mathbf{n / a}$ & & $\boldsymbol{n} / \boldsymbol{a}$ & $\mathbf{1 4 0 . 3}$ & $\mathbf{2 . 0 \%}$ \\
\hline
\end{tabular}

In the last 12-month period before the price reduction was in place (July 2014 - June 2015, Table I), prescription drugs represented almost two thirds $(63.0 \%)$ of the volume of medical drug treatment in Romania, four fifths $(79.1 \%)$ of the value at final prices and covering $84.7 \%$ of the total drug treatment days of all patients in Romania.

The hospitals, though deserving of a more in-depth analysis, present too many specificities which would make the current analysis more complex and difficult. The OTC drugs are deregulated, mainly because they do not suppose any expense of public funds; an indepth analysis would be more than necessary with regards to this segment as well, though it does not constitute the object of this article.

\section{Materials and Methods}

As analysis material we have used the information contained in the market studies developed over the years and made available by the Cegedim group.

As interpretation methods we have used the following: (i) The analysis of the increase/decrease of absolute values: volume (no. units/boxes), value (RON), number of treatment days, price (RON); (ii) The analysis of increase/decrease of relative values: the weighting of an element or of a relevant category as part of the total; (iii) The analysis of increase/decrease of product, brands and INNs in a time interval; (iv) The analysis of increase/decrease of number of pharmaceutical products, of the volume and the value for price categories.

Concerning the value and price expressed in RON (Romanian national currency), we mention that 1 EURO represents approximatively $5 \mathrm{RON}$, according to Romanian National Bank exchange rate [27].

We must underline the distinction between the drug from a scientific point of view (substance $=I N N$ or combination of substances responsible for therapeutic effects) and the commercial point of view (pharmaceutical product with name/brand, pharmaceutical form, INN/ combination of INNs, concentration, volume/ packaging and producer and price), because any price policy addresses the second (the commercial) one. Statistical analysis was performed using the open source software $\mathrm{R}$ [8]. Due to the relatively small number of elements related to each factor involved we used in our statistical evaluation a bootstrap approach [16]. The evaluation of the statistical differences of the some type of data was performed with the help of the one way analysis of variance (one way ANOVA), unbalanced design. We decide if the differences between the studied samples are significant using the 5\% standard level of significance $(\mathrm{p}<0.05)$. 
FARMACIA, 2021, Vol. 69, 3

\section{Results and Discussion}

The evolution of Rx products at a national level In Romania, there is a policy of price control just for prescription-only medicines [12, 14, 20]. The comparable situation (July 2018 - June 2019) of drug consumption after 4 years since the adoption of the price regulation for $\mathrm{Rx}$ products is found in Table II.

Table II

Drug consumption in the period of July 2018 - June 2019

\begin{tabular}{|l|c|c|c|c|c|c|c|c|c|}
\hline \multirow{2}{*}{ Segment } & \multicolumn{2}{|c|}{ Volume (Units) } & \multicolumn{2}{c|}{ PPP Value } & \multicolumn{2}{c|}{ CPP Value } & \multicolumn{2}{c|}{ CPP Average Price } & \multicolumn{2}{c|}{ Days of treatment } \\
\cline { 2 - 10 } & mil. & $\%$ & mil. Lei & $\%$ & mil. Lei & $\%$ & Lei & mil. & $\%$ \\
\hline Total & $\mathbf{6 2 5 . 9}$ & $\mathbf{1 0 0 \%}$ & $\mathbf{1 7 , 5 3 2 . 7}$ & $\mathbf{1 0 0 \%}$ & $\mathbf{1 8 , 8 2 9 . 5}$ & & $\mathbf{3 0 . 0 9}$ & $\mathbf{8 , 5 0 0 . 4}$ & $\mathbf{1 0 0 \%}$ \\
\hline Pharmacies & $\mathbf{5 9 5 . 4}$ & $\mathbf{9 5 . 1 \%}$ & $\mathbf{1 5 , 4 2 9 . 5}$ & $\mathbf{8 8 . 0 \%}$ & $\mathbf{1 8 , 8 2 9 . 5}$ & $\mathbf{1 0 0 \%}$ & $\mathbf{3 1 . 6 3}$ & $\mathbf{8 , 3 3 9 . 2}$ & $\mathbf{9 8 . 1 \%}$ \\
\hline OTC & 215.9 & $34.5 \%$ & $3,833.0$ & $21.9 \%$ & $4,546.9$ & $24.1 \%$ & 21.06 & $1,221.9$ & $14.4 \%$ \\
\hline Rx & 379.5 & $60.6 \%$ & $11,596.5$ & $66.1 \%$ & $14,282.6$ & $75.9 \%$ & 37.63 & $7,117.3$ & $83.7 \%$ \\
\hline - Innovator $R x$ & 152.3 & $24.3 \%$ & $8,796.7$ & $50.2 \%$ & $10,515.6$ & $55.8 \%$ & 69.02 & $3,128.3$ & $36.8 \%$ \\
\hline - Generic $R x$ & 227.2 & $36.3 \%$ & $2,799.8$ & $16.0 \%$ & $3,767.0$ & $20.0 \%$ & 16.58 & $3,989.0$ & $46.9 \%$ \\
\hline Hospitals & $\mathbf{3 0 . 5}$ & $\mathbf{4 . 9 \%}$ & $\mathbf{2 , 1 0 3 . 1}$ & $\mathbf{1 2 . 0 \%}$ & $\mathbf{n / a}$ & $\mathbf{0 . 0 \%}$ & $\mathbf{n / a}$ & $\mathbf{1 6 1 . 3}$ & $\mathbf{1 . 9 \%}$ \\
\hline
\end{tabular}

The main variations between the 2 analysed periods (Table II compared with Table I) for the Rx drugs are as follows: (i) The volume of Rx drugs has increased by $11.0 \%$ (from $341.81 \mathrm{mil}$. Units to $379.52 \mathrm{mil}$. units), but their weighting has decreased from $63.0 \%$ to $60.6 \%$ of the total volume, in favour of OTC drugs, while hospitals have kept their weighting $(4,9 \%)$; (ii) The value of Rx drugs in terms of retail pricing (CPP) has grown by $31.5 \%$ (from 10.86 bil. RON to 14.28 bil. RON), but the proportion decreased from $79.1 \%$ to $75.9 \%$ of the total value, in favour of OTC drugs; (iii) The number of treatment days for Rx drugs has increased by 20,8\% (from 5,89 bil. DoT to 7,12 bil. DoT), but the weighting has decreased from $84.7 \%$ to $83.7 \%$ of the total treatment days, in favour of OTC drugs; (iv) The average price of Rx drugs has increased from $18.4 \%$ (from $31.77 \mathrm{RON} /$ box to 37.63 RON/box).

Apparently, due to the fact that in the 4 years since the regulation both the volume and the value and the number of treatment days have increased, one can state that the access to treatment for patients in Romania has grown.

We consider such statement as a superficial conclusion since: (i) The growth in volume by $11.0 \%$ in 4 years (equivalent to an average growth of $2.65 \%$ each year) is insignificant when compared with the motivation behind the regulation; although difficult to establish precisely, a growth of $25-30 \%$ would have been actually relevant; (ii) The decrease of the proportion of Rx treatments (as volume, value and days of treatment) in favour of OTC treatments, the latter being paid in full by the patients, confirms the deficit with which this segment is managed; we are of the opinion that there is still an imbalance between demand (a great need for treatment) and supply (forcibly reduced due to prices); (iii) The main goal, the reduction of (average) drug prices has not been achieved.

Evolution of Rx products: Generics vs Innovators In Romania, generic substitution and International Non-Proprietary Name (INN) prescribing are allowed, being indicative for the prescriber [21]. The innovator
Rx drugs (with or without patent protection) displayed the following behaviour: (i) They have increased in volume by $20.9 \%$ (from 126.02 mil. units to 152.36 mil. units) and their weighting has increased from $23.2 \%$ to $24.3 \%$ of the total treatments; (ii) They have increased by $41.9 \%$ in terms of CPP value (from 7.41 bil. RON to 10.51 bil. RON) and their weighting has increased from $53.9 \%$ to $55.8 \%$ of the total treatments; (iii) They have increased in terms of number of treatment days by $30,8 \%$ (from 2.39 bil. DoT to 3.13 bil. DoT), while the proportion has grown from $34.4 \%$ to $36.8 \%$ of the total treatments; (iv) The average price has increased by $18.4 \%$ (from $58.78 \mathrm{RON} / \mathrm{box}$ to $69.02 \mathrm{RON} /$ box).

The generic Rx drugs have evolved in this manner: (i) They have grown by $5.3 \%$ in volume (from 215.79 mil. units to 227.17 mil. units) and their proportion decreased from $39.7 \%$ la $36.3 \%$ of total treatments; (ii) They have grown by $9.1 \%$ in CPP value (from 3.45 bil. RON to 3.77 bil. RON) and their weighting has decreased from $25.1 \%$ to $20.0 \%$ of total treatments; (iii) They have increased in terms of number of treatment days by $13.9 \%$ (from 3.50 bil. DoT to 3.99 bil. DoT), while their proportion decreased from $50.3 \%$ to $46.9 \%$ of total treatments; (iv) The average price has grown by $3.6 \%$ (from $16.00 \mathrm{RON} /$ box to $16.58 \mathrm{RON} / \mathrm{box}$ ); the decrease of the average price for generic Rx drugs (16.58 RON/box) below the average price for OTC drugs (21.06 RON/box) represents a bizarre phenomenon, unknown to mature markets.

One can say that the price regulation had the following effects: (i) Effects of low significance for innovator drugs, especially those that are protected by patents, because the minimum price mechanism addresses only those segments of the market where there is direct competition; for those drugs whose patent protection has expired there is observed either a high degree of transformation to generics or the acceleration of the exit of the INN from the market; (ii) Significant effects (in terms of cost control) for generic drugs, however this comes at the price of reducing their proportion, which in turn, definitively does not help 
FARMACIA, 2021, Vol. 69, 3

increase treatment accessibility, especially for basic drugs.

In terms of policies, the generic drugs have been discriminated by these regulations, even more so since the budget control mechanism ("claw-back") is being applied uniformly, in terms of total increase in the cost of drugs.

The evolution of Rx products according to settlement type

The above analysis can be expanded to the level of the different settlement categories: (i) Important Cities (cities with well-established medical universities or with over 250,000 inhabitants); (ii) Medium Cities (cities with between 50,000 to 250,000 inhabitants); (iii) Small Towns (towns with less than 50.000 inhabitants and the rural areas).

The situation of drug consumption in the period of July 2014 - June 2015 can be found in Table III.

If we study the comparable time period (July 2018 June 2019, Table IV) with the reference one (Table III) according to the specific of the areas from which the patients get their treatment from we have the following information.

Drug consumption by settlement type between July 2014 and June

\begin{tabular}{|c|c|c|c|c|c|c|c|c|}
\hline \multirow[t]{2}{*}{ Area Type } & \multirow[t]{2}{*}{ Segment } & \multicolumn{2}{|c|}{ Volume (Units) } & \multicolumn{2}{|c|}{ CPP Value } & \multirow{2}{*}{$\begin{array}{c}\text { CPP Average Price } \\
\text { RON }\end{array}$} & \multicolumn{2}{|c|}{ Days of treatment } \\
\hline & & mil. & $\%$ & mil. RON & $\%$ & & mil. & $\%$ \\
\hline \multirow{5}{*}{$\begin{array}{l}\text { Important } \\
\text { Cities }\end{array}$} & Total & 193.50 & $100.0 \%$ & $6,062.49$ & $100.0 \%$ & 31.33 & $2,596.80$ & $100.0 \%$ \\
\hline & OTC & 71.38 & $36.9 \%$ & $1,241.43$ & $20.5 \%$ & 17.39 & 376.97 & $14.5 \%$ \\
\hline & $\mathrm{Rx}$ & 122.12 & $63.1 \%$ & $4,821.06$ & $79.5 \%$ & 39.48 & $2,219.83$ & $85.5 \%$ \\
\hline & - Innovator $R x$ & 51.00 & $26.4 \%$ & $3,523.82$ & $58.1 \%$ & 69.10 & 981.64 & $37.8 \%$ \\
\hline & - Generic Rx & 71.12 & $36.8 \%$ & $1,297.24$ & $21.4 \%$ & 18.24 & $1,238.19$ & $47.7 \%$ \\
\hline \multirow{5}{*}{$\begin{array}{l}\text { Medium } \\
\text { Cities }\end{array}$} & Total & 139.34 & $100.0 \%$ & $3,940.20$ & $100.0 \%$ & 28.28 & $1,825.92$ & $100.0 \%$ \\
\hline & OTC & 47.96 & $34.4 \%$ & 795.48 & $20.2 \%$ & 16.59 & 248.53 & $13.6 \%$ \\
\hline & $\mathrm{Rx}$ & 91.39 & $65.6 \%$ & $3,144.71$ & $79.8 \%$ & 34.41 & $1,577.39$ & $86.4 \%$ \\
\hline & - Innovator Rx & 34.18 & $24.5 \%$ & $2,199.01$ & $55.8 \%$ & 64.34 & 657.45 & $36.0 \%$ \\
\hline & - Generic $R x$ & 57.21 & $41.1 \%$ & 945.70 & $24.0 \%$ & 16.53 & 919.94 & $50.4 \%$ \\
\hline \multirow{5}{*}{$\begin{array}{l}\text { Small } \\
\text { Towns }\end{array}$} & Total & 183.72 & $100.0 \%$ & $3,729.03$ & $100.0 \%$ & 20.30 & $2,395.77$ & $100.0 \%$ \\
\hline & OTC & 55.42 & $30.2 \%$ & 835.01 & $22.4 \%$ & 15.07 & 299.87 & $12.5 \%$ \\
\hline & $\mathrm{Rx}$ & 128.31 & $69.8 \%$ & $2,894.02$ & $77.6 \%$ & 22.56 & $2,095.89$ & $87.5 \%$ \\
\hline & - Innovator Rx & 40.84 & $22.2 \%$ & $1,684.26$ & $45.2 \%$ & 41.24 & 752.05 & $31.4 \%$ \\
\hline & - Generic $R x$ & 87.47 & $47.6 \%$ & $1,209.75$ & $32.4 \%$ & 13.83 & $1,343.84$ & $56.1 \%$ \\
\hline
\end{tabular}

Table IV

Drug consumption by settlement type between July 2018 and June 2019

\begin{tabular}{|c|c|c|c|c|c|c|c|c|}
\hline \multirow[t]{2}{*}{ Area Type } & \multirow[t]{2}{*}{ Segment } & \multicolumn{2}{|c|}{ Volume (Units) } & \multicolumn{2}{|c|}{ CPP Value } & \multirow{2}{*}{$\frac{\text { CPP Average Price }}{\text { RON }}$} & \multicolumn{2}{|c|}{ Days of treatment } \\
\hline & & mil. & $\%$ & mil. RON & $\%$ & & mil. & $\%$ \\
\hline \multirow{5}{*}{$\begin{array}{l}\text { Important } \\
\text { Cities }\end{array}$} & Total & 213.07 & $100.0 \%$ & $8,821.09$ & $100.0 \%$ & 41.40 & $3,011.40$ & $100.0 \%$ \\
\hline & OTC & 84.35 & $39.6 \%$ & $1,863.15$ & $21.1 \%$ & 22.09 & 497.69 & $16.5 \%$ \\
\hline & $\mathrm{Rx}$ & 128.72 & $60.4 \%$ & $6,957.94$ & $78.9 \%$ & 54.05 & $2,513.71$ & $83.5 \%$ \\
\hline & - Innovator $R x$ & 57.56 & $27.0 \%$ & $5,604.55$ & $63.5 \%$ & 97.37 & $1,182.51$ & $39.3 \%$ \\
\hline & - Generic Rx & 71.17 & $33.4 \%$ & $1,353.39$ & $15.3 \%$ & 19.02 & $1,331.19$ & $44.2 \%$ \\
\hline \multirow{5}{*}{$\begin{array}{l}\text { Medium } \\
\text { Cities }\end{array}$} & Total & 163.53 & $100.0 \%$ & $5,102.61$ & $100.0 \%$ & 31.20 & $2,283.69$ & $100.0 \%$ \\
\hline & OTC & 59.59 & $36.4 \%$ & $1,278.74$ & $25.1 \%$ & 21.46 & 326.16 & $14.3 \%$ \\
\hline & $\mathrm{Rx}$ & 103.94 & $63.6 \%$ & $3,823.87$ & $74.9 \%$ & 36.79 & $1,957.53$ & $85.7 \%$ \\
\hline & - Innovator $R x$ & 42.53 & $26.0 \%$ & $2,752.27$ & $53.9 \%$ & 64.71 & 879.02 & $38.5 \%$ \\
\hline & - Generic $R x$ & 61.41 & $37.6 \%$ & $1,071.60$ & $21.0 \%$ & 17.45 & $1,078.51$ & $47.2 \%$ \\
\hline \multirow{5}{*}{$\begin{array}{l}\text { Small } \\
\text { Towns }\end{array}$} & Total & 218.80 & $100.0 \%$ & $4,905.83$ & $100.0 \%$ & 22.42 & $3,044.09$ & $100.0 \%$ \\
\hline & OTC & 71.94 & $32.9 \%$ & $1,404.98$ & $28.6 \%$ & 19.53 & 398.02 & $13.1 \%$ \\
\hline & $\mathrm{Rx}$ & 146.86 & $67.1 \%$ & $3,500.85$ & $71.4 \%$ & 23.84 & $2,646.08$ & $86.9 \%$ \\
\hline & - Innovator Rx & 52.27 & $23.9 \%$ & $2,158.87$ & $44.0 \%$ & 41.31 & $1,066.76$ & $35.0 \%$ \\
\hline & - Generic $R x$ & 94.59 & $43.2 \%$ & $1,341.98$ & $27.4 \%$ & 14.19 & $1,579.32$ & $51.9 \%$ \\
\hline
\end{tabular}

In the important cities (cities with universities or with over 250,000 inhabitants), the evolution has been the following: (i) In terms of volume, the Rx drugs have grown by $5.4 \%$ (from 122.12 mil. units to 128.72 mil. units), the innovator ones by $12.9 \%$ (from 51.00 mil. units to 57.56 mil. units), while the generic drugs have stagnated (a $0.1 \%$ growth, from 71.12 mil. units to
71.17 mil. units). From the statistical analysis we can say that there are two main effects relative to the type of segment $(p<0.001)$ and the type of city in the study $(p=0.014)$. We can say that there is no statistical interaction between the years under research $(2015$ or 2019) and the other factors under study ( $p>0.05$ ); (ii) As far as value is concerned, the Rx drugs have 
increased by $44.3 \%$ (from 4.82 bil. RON to 6.96 bil. RON), the inovator ones by $59.0 \%$ (from 3.52 bil. RON to 5.60 bil. RON), while the generic ones have increased by $4.3 \%$ (from 1.30 bil. RON to 1.35 bil. $\mathrm{RON}$ ); (iii) In terms of days of treatment, the $\mathrm{Rx}$ drugs have increased by $13.2 \%$ (from 2.22 bil. DoT to 2.51 bil. DoT), the inovator ones by $20.5 \%$ (from 0.98 bil. DoT to 1.18 bil. DoT), while the generic ones have increased by $7.5 \%$ (from 1.24 bil. DoT to 1.33 bil. DoT). From the statistical analysis we can say that it is only one main effect relative to the type of segment $(\mathrm{p}<0.001)$. We can say that there is no statistical interaction between the years under research (2015 or 2019) and the other factors under study ( $p>0.05$ ); (iv) The average price has increased for all Rx drugs by $36.9 \%$ (from $39.48 \mathrm{RON} / \mathrm{box}$ to $54.05 \mathrm{RON} / \mathrm{box}$ ), the innovator ones by $40.9 \%$ (from 69.10 RON/box to $97.37 \mathrm{RON} / \mathrm{box}$ ), while the generics have increased by $4.3 \%$ (from $18.24 \mathrm{RON} /$ box to 19.02 RON/box).

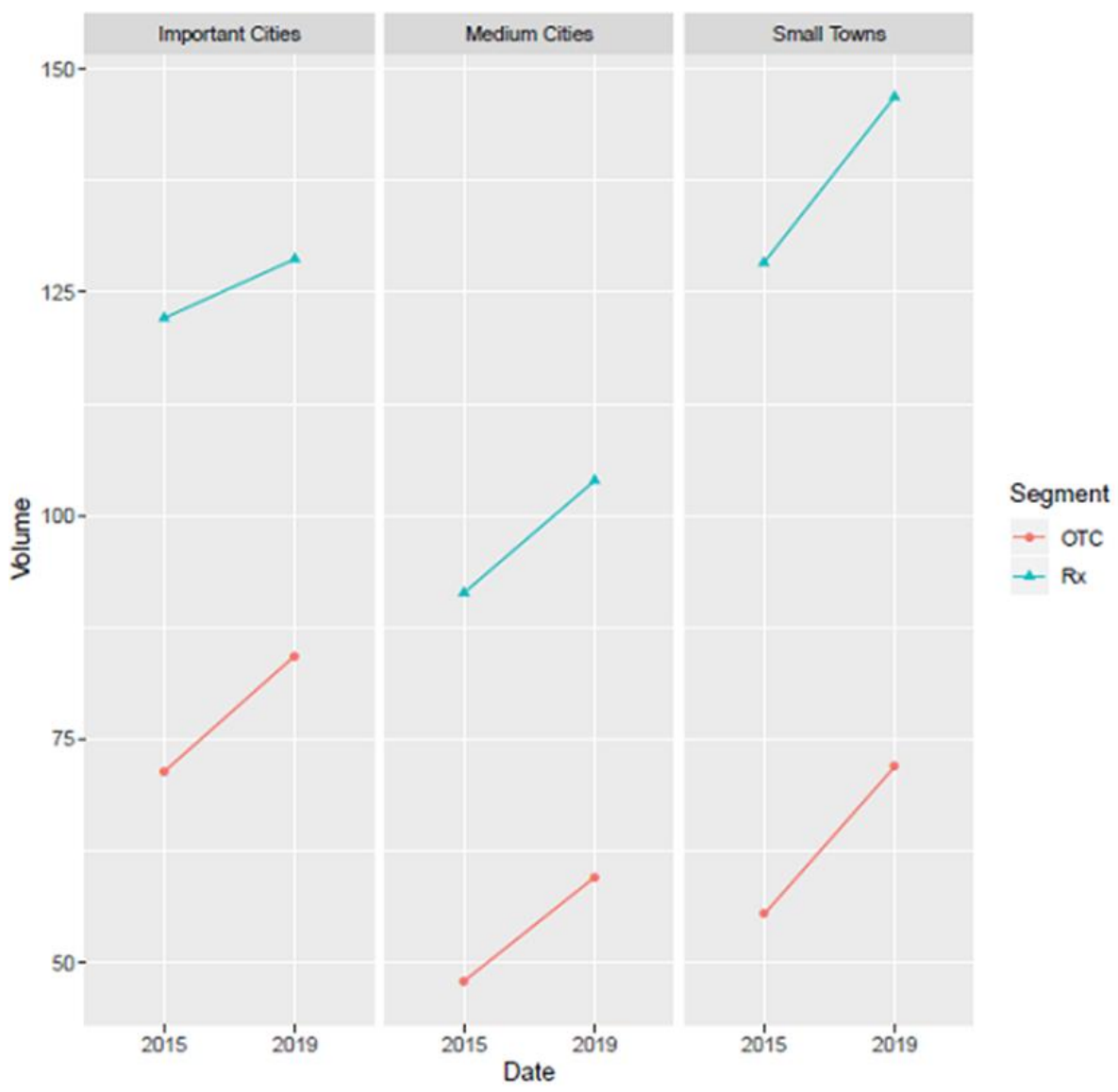

Figure 1.

Drug consumption by settlement in terms of volume

In the medium cities (50.000 - 250.000 inhabitants), there was the following evolution: (i) In terms of volume, the Rx drugs have grown by $13.7 \%$ (from 91.39 mil. units to 103.94 mil. units), the innovator ones by $24.4 \%$ (from 34.18 mil. units to $42.53 \mathrm{mil}$. units) and the generic ones by $7.3 \%$ (from $57.21 \mathrm{mil}$. units to 61.41 mil. units); (ii) In terms of value, the Rx drugs have grown by $21.6 \%$ (from 3.14 bil. RON to 3.82 bil. RON), the innovator ones by $25.1 \%$ (from 2.20 bil. RON to 2.75 bil. RON), while the generic drugs have grown by $13.3 \%$ (from 0.95 bil. RON to 1.07 bil. RON); (iii) As far as treatment days are concerned, the Rx drugs have grown by $24.1 \%$ (from 1.58 bil. DoT to 1.96 bil. DoT), the innovator ones by $33.7 \%$ (from 0.66 bil. DoT to 0.88 bil. DoT) and the generic ones by $17.2 \%$ (from 0.92 bil. DoT to 1.08 bil. DoT); (iv) The average price has grown for the entire Rx drugs category by $6.9 \%$ (from $34.41 \mathrm{RON} / \mathrm{box}$ to $36.79 \mathrm{RON} / \mathrm{box}$ ), the innovator ones having grown by $0.5 \%$ (from $64.34 \mathrm{RON} / \mathrm{box}$ to $64.71 \mathrm{RON} / \mathrm{box}$ ) and the generic ones by $5.6 \%$ (from 16.53 RON/box to $17.45 \mathrm{RON} / \mathrm{box}$ ).

In small cities $(<50.000$ inhabitants) and village, the evolution has been the following: (i) In terms of volume, the Rx drugs have grown by $14.4 \%$ (from 128.31 mil. units to 146.86 mil. units), the innovator ones by $28.0 \%$ (from 40.84 mil. units to $52.27 \mathrm{mil}$. units) and the generic ones by $8.1 \%$, from $87.47 \mathrm{mil}$. units to 94.59 mil. units); (ii) In terms of value, the Rx drugs have grown by $20.9 \%$ (from 2.89 bil. RON to 3.50 bil. RON), the innovator ones by $28.2 \%$ (from 1.68 bil. RON to 2.16 bil. RON) and the generic ones 
by $10.9 \%$ (from 1.21 bil. RON to 1.34 bil. RON); (iii) In terms of days of treatment, the Rx drugs have increased by $26.2 \%$ (from 2.10 bil. DoT to 2.65 bil. DoT), the innovator drugs by $41.8 \%$ (from 0.75 bil. DoT to 1.07 bil. DoT), while the generic ones have increased by $17.5 \%$ (from 1.34 bil. DoT to 1.58 bil.
DoT); (iv) The average price has increased for all Rx drugs by $5.7 \%$ (from $22.56 \mathrm{RON} / \mathrm{box}$ to 23.84 RON/box), the innovator drugs having grown by $0.1 \%$ (from $41.24 \mathrm{RON} / \mathrm{box}$ to $41.31 \mathrm{RON} / \mathrm{box}$ ) and the generic ones by $2.6 \%$ (from $13.83 \mathrm{RON} / \mathrm{box}$ to 14.19 RON/box).

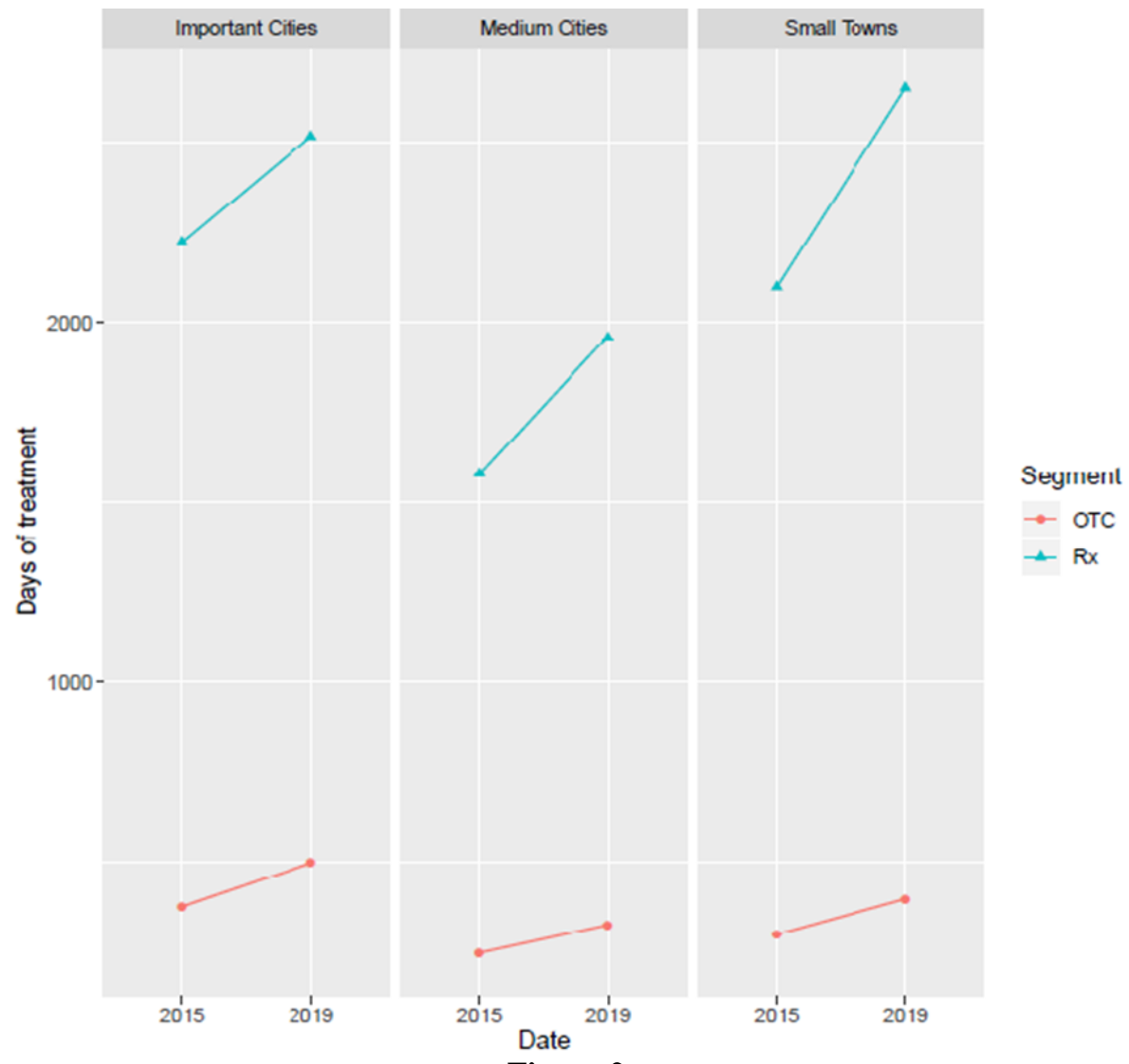

Figure 2.

Drug consumption by settlement in terms of days of treatment

Although from an economical point of view, the correlation of average prices and ratios of product categories with the average purchasing power for each area type is no surprise, from a professional and social standpoint, the increasingly polarizing nature of the drug assistance system, as well as the unequal access to treatment for patients from different environments is worrying, to say the least. Studies also had indicated a low accessibility to pharmacies and drugs in the rural areas from Romania [21].
The evolution of the number of products and INNS In order to complete the evolution analysis from the therapeutic point of view, we should look at the number of INNs and products that had a persistent presence on the market, as well as at the success rate of newly entered products in the market. In mid-2015 we had in Romania, in term of INNs 936 items on the market; the evolution of the total number of INNs can be followed in Table V.

Table V

The number of INNs in the period of July 2014 - June 2019

\begin{tabular}{|l|c|c|c|c|c|c|c|}
\hline \multicolumn{1}{|c|}{ INN Market Category } & $\begin{array}{c}\text { No. INNs } \\
2015-06\end{array}$ & $\begin{array}{c}\text { No. INNs } \\
2015-12\end{array}$ & $\begin{array}{c}\text { No. INNs } \\
2016-12\end{array}$ & $\begin{array}{c}\text { No. INNs } \\
2017-12\end{array}$ & $\begin{array}{c}\text { No. INNs } \\
2018-12\end{array}$ & $\begin{array}{c}\text { No. INNs } \\
2019-06\end{array}$ & $\begin{array}{c}\text { Total } \\
\text { INNs }\end{array}$ \\
\hline Total INNs present & $\mathbf{9 3 6}$ & $\mathbf{9 4 4}$ & $\mathbf{9 2 2}$ & $\mathbf{9 3 6}$ & $\mathbf{9 5 8}$ & $\mathbf{9 6 3}$ & - \\
\hline INN entries & & 20 & 25 & 39 & 45 & 22 & $\mathbf{1 5 1}$ \\
\hline INN exits & & 12 & 47 & 25 & 23 & 17 & $\mathbf{1 2 4}$ \\
\hline
\end{tabular}

Although at first sight the evolution is positive, the total number of INNs having slightly grown due to the fact that during this time period 151 INNs entered on the market (more than the 124 INN exits) and only in 2016 did the number of INNs exiting the market surpass the number of INNs entering it, there remains the question whether all those 124 INNs that have exited the market in these 4 years presented or lacked 
real therapeutic benefits or whether their cost/benefit ratio was unsuitable.

At the product-level (products in various forms, concentrations, with different packaging, from different producers) we were registering in Romania in June 2015 over 4,000 items (Table VI).

One can observe that the average number of products per INN is 4.5 which means a moderate level of competition; this is much higher, perceptibly so, in the categories with greater sales (17.3 products/INN for sales over 120 mil. RON/year at CPP level and 10.0 products/INN for sales between 12 and 120 mil. RON/ year, respectively) and much lower in the lesser sales categories ( 2.0 products/INN for sales between 0.12 and $1.2 \mathrm{mil}$. RON/year, and 1.3 products/INN for sales under 120,000 RON/year).

Table VI

The number of INNs and products in the period of July 2014 - June 2015

\begin{tabular}{|c|c|c|c|c|c|c|c|c|}
\hline \multirow[t]{2}{*}{ Category } & \multirow{2}{*}{$\begin{array}{l}\text { Number } \\
\text { of INNs }\end{array}$} & \multirow{2}{*}{$\begin{array}{c}\text { Number of } \\
\text { Products } \\
2015-06\end{array}$} & \multirow{2}{*}{$\begin{array}{l}\text { No. Products/ } \\
\text { INN (average) }\end{array}$} & \multicolumn{2}{|c|}{ Volume (Units) } & \multicolumn{2}{|c|}{ CPP Value } & \multirow{2}{*}{\begin{tabular}{|c}
$\begin{array}{c}\text { Average CPP } \\
\text { Price }\end{array}$ \\
RON
\end{tabular}} \\
\hline & & & & mil. RON & $\%$ & mil. RON & $\%$ & \\
\hline Total Rx & 936 & 4,191 & 4.5 & 341.8 & $100 \%$ & \begin{tabular}{|l|}
$10,859.8$ \\
\end{tabular} & $100.0 \%$ & 31.77 \\
\hline \begin{tabular}{|l|} 
Important Sales \\
(over 120 mil. RON/year)
\end{tabular} & 15 & 260 & 17.3 & 45.4 & $13.3 \%$ & $2,349.9$ & $21.6 \%$ & 51.74 \\
\hline \begin{tabular}{|l|} 
Significant Sales \\
$(12-120$ mil. RON/year $)$
\end{tabular} & 195 & 1,957 & 10.0 & 202.3 & $59.2 \%$ & $6,807.7$ & $62.7 \%$ & 33.65 \\
\hline \begin{tabular}{|l|} 
Medium Sales \\
$(1.2-12$ mil. RON/year $)$
\end{tabular} & 340 & 1,330 & 3.9 & 87.0 & $25.4 \%$ & $1,577.7$ & $14.5 \%$ & 18.14 \\
\hline $\begin{array}{l}\text { Precarious Sales (0.12 - } 1.2 \\
\text { mil. RON/year) }\end{array}$ & 229 & 447 & 2.0 & 6.9 & $2.0 \%$ & 118.2 & $1.1 \%$ & 17.19 \\
\hline $\begin{array}{l}\text { Insignificant Sales } \\
\text { (under 120,000 RON/year) }\end{array}$ & 157 & 197 & 1.3 & 0.2 & $0.1 \%$ & 6.3 & $0.1 \%$ & 34.10 \\
\hline
\end{tabular}

There is no direct correlation between the average price and the level of sales, because the frequency and severity of diseases differ and are in a continual dynamic; also the competition differs by therapeutic sub-segments. Just as a mention, the almost 1,000 INNs are used to treat the vast majority of known diseases, which are about 1,000 in the current codification system of Romania (CIM); however, in the international standard (ICD 10) there are almost 3,000 distinct items. The standardization of treatment by disease remains an aspirational objective for Romania, therefore the responsibility and experience of the prescribing doctor is the main factor to sustain the efficiency of the drug treatment in time, so it should not be endangered at every opportunity.

The evolution of products in terms of the level of sales during the period of July 2014 - June 2019 can be followed in Table VII. The number of products (in terms of absolute value) has been reduced in every product category, the drop being, of course, more severe for products belonging to INNs with insignificant sales. Particular attention must be given to the fact that there exists a difference between the number of authorized products (allowed on the market) and the actual number of products available on the market. This difference is explained by an essentially commercial decision, taken by the companies responsible for the respective products which follows the economic rationality (in time, the income from sales must exceed the sum of the production costs, the commercialization costs and the corresponding taxes).There is, of course, a certain inertia in a given period of time, but sudden withdrawals of drugs from the market are usually caused by the presence of adverse effects and only rarely due to purely economic reasons.

Table VII

The evolution of the Number of Products during the period of July 2014 - June 2019 for the INNs present in July

2014 - June 2015 in terms of the level of Sales in 2015

\begin{tabular}{|l|c|c|c|c|c|c|c|}
\hline \multicolumn{1}{|c|}{ Category } & No. & \multicolumn{7}{c|}{ No. Products } \\
\cline { 5 - 9 } & INNs & $2015-06$ & $2015-12$ & $2016-12$ & $2017-12$ & $2018-12$ & $2019-06$ \\
\hline Total Rx & $\mathbf{9 3 6}$ & $\mathbf{4 , 1 9 1}$ & $\mathbf{4 , 1 9 2}$ & $\mathbf{3 , 9 1 7}$ & $\mathbf{3 , 8 5 7}$ & $\mathbf{3 , 7 9 2}$ & $\mathbf{3 , 8 3 3}$ \\
\hline Important Sales (over 120 mil. RON/year) & 15 & 260 & 246 & 215 & 190 & 197 & 228 \\
\hline Significant Sales (12-120 mil. RON/year) & 195 & 1,957 & 1,888 & 1,699 & 1,687 & 1,620 & 1,626 \\
\hline Medium Sales (1.2-12 mil. RON/year) & 340 & 1,330 & 1,266 & 1,152 & 1,102 & 1,082 & 1,134 \\
\hline Precarious Sales (0.12-1.2 mil. RON/year) & 229 & 447 & 436 & 394 & 383 & 362 & 385 \\
\hline Insignificant Sales (under 120,000 RON/year) & 157 & 197 & 177 & 128 & 108 & 103 & 117 \\
\hline Product Entries & & & 179 & 301 & 326 & 292 & 178 \\
\hline Product Exits & & & 178 & 576 & 386 & 357 & 137 \\
\hline
\end{tabular}

This reduction would have been even more dramatic had we not recorded in these 4 years the entry of
1,276 new products, since in this time period there have exited the market 1,634 products, that is $39.0 \%$ 
of the products present before the price regulations of 1 July 2015 had come into force. Likewise, there must be mentioned the fact that not only the market presence is of importance, but also the presence in sufficient amounts; in its absence, we witness the establishing of the term of "in-deficit drugs" within the supply chain (producers, distributors, pharmacies), which means drugs whose orders are regularly partially fulfilled (in the best case scenario) and/or come with accompanying difficulties (delayed time frames, disadvantageous prices/conditions etc.). Following the statistical evaluation we are able to state that there is a statistically significant difference between the 5 types of categories $(p<0.001)$, but the effect of time does not interact significantly on the differences relative to product sales [6].

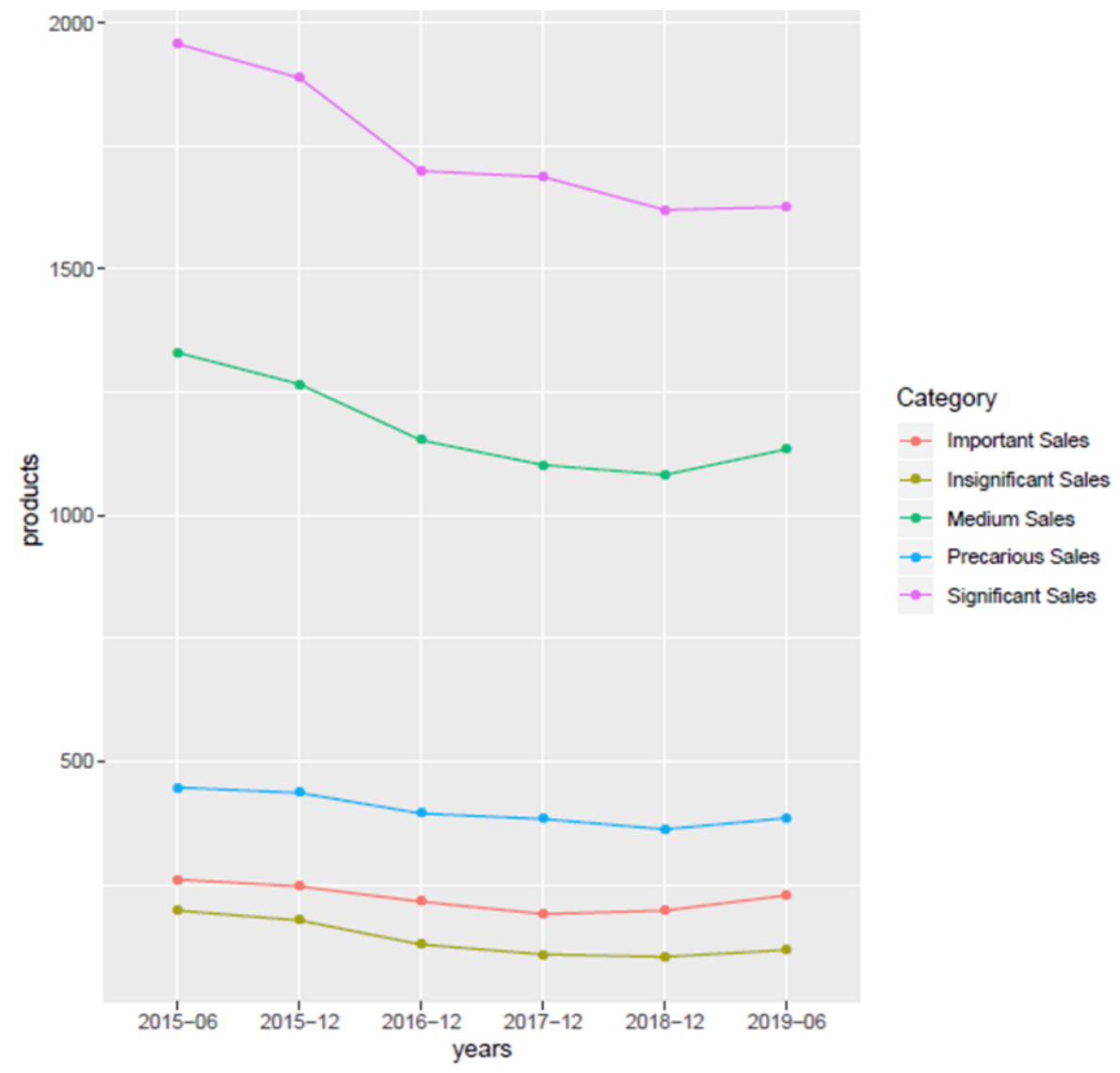

Figure 3.

The evolution of the Number of Products

Table VIII

The evolution of INN and Product Numbers between July 2018 and June 2019

\begin{tabular}{|c|c|c|c|c|c|c|c|c|}
\hline \multirow[t]{2}{*}{ Category } & \multirow{2}{*}{$\begin{array}{l}\text { Number } \\
\text { of INNs }\end{array}$} & \multirow{2}{*}{$\begin{array}{l}\text { Number of } \\
\text { Products } \\
2019-06\end{array}$} & \multirow{2}{*}{\begin{tabular}{|c|} 
No. \\
Products/ \\
INN
\end{tabular}} & \multicolumn{2}{|c|}{ Volume (Units) } & \multicolumn{2}{|c|}{ CPP Value } & \multirow{2}{*}{$\begin{array}{c}\text { Average } \\
\text { CPP Price } \\
\text { RON }\end{array}$} \\
\hline & & & & mil. RON & $\%$ & mil. RON & $\%$ & \\
\hline Total Rx & 963 & 5,140 & 5.3 & 379.5 & $100 \%$ & $14,282.6$ & $100.0 \%$ & 37.63 \\
\hline $\begin{array}{l}\text { Important Sales } \\
\text { (over } 120 \text { mil. RON/year) }\end{array}$ & 17 & 297 & 17.5 & 57.1 & $15.0 \%$ & $4,385.5$ & $30.7 \%$ & 76.82 \\
\hline $\begin{array}{l}\text { Significant Sales } \\
(12 \text { - } 120 \text { mil. RON/year })\end{array}$ & 212 & 2,350 & 11.1 & 223.6 & $58.9 \%$ & $7,895.4$ & $55.3 \%$ & 35.31 \\
\hline $\begin{array}{l}\text { Medium Sales } \\
(1.2-12 \text { mil. RON/year })\end{array}$ & 367 & 1,694 & 4.6 & 92.4 & $24.3 \%$ & $1,866.3$ & $13.1 \%$ & 20.20 \\
\hline $\begin{array}{l}\text { Precarious Sales } \\
(0.12-1.2 \text { mil. RON/year })\end{array}$ & 230 & 576 & 2.5 & 6.3 & $1.7 \%$ & 130.4 & $0.9 \%$ & 20.54 \\
\hline $\begin{array}{l}\text { Insignificant Sales } \\
\text { (under } 120,000 \text { RON/year) }\end{array}$ & 137 & 223 & 1.6 & 0.1 & $0.0 \%$ & 5.1 & $0.0 \%$ & 42.08 \\
\hline
\end{tabular}

Newly-entered products have been numerous (not just for existing INNs, but also for new INNs), though not all have been successful, such that the structure of the Romanian market halfway through 2019 in terms of INNs and products can be observed in Table VIII, where one can notice the increase of average 
price for each sales category compared to 4 years ago (see the data from Table VI).

The data from Tables VI and VIII are cumulated in Figure 4 and thus we can evaluate the differences in terms of INNs and products relative to the time factor). From the statistical analysis on the evaluation of the

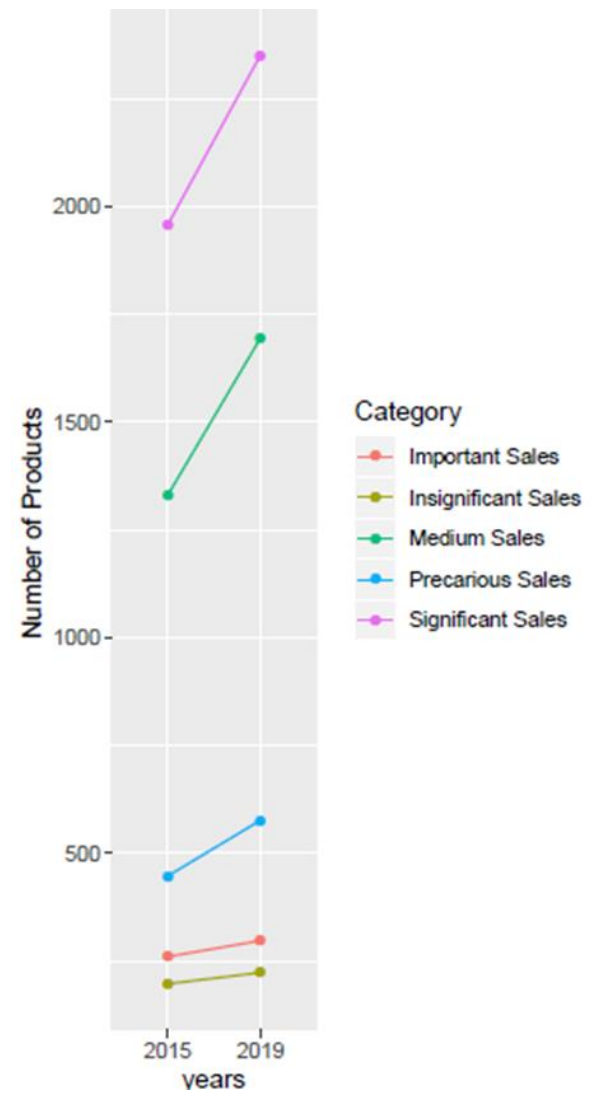

Figure 4.

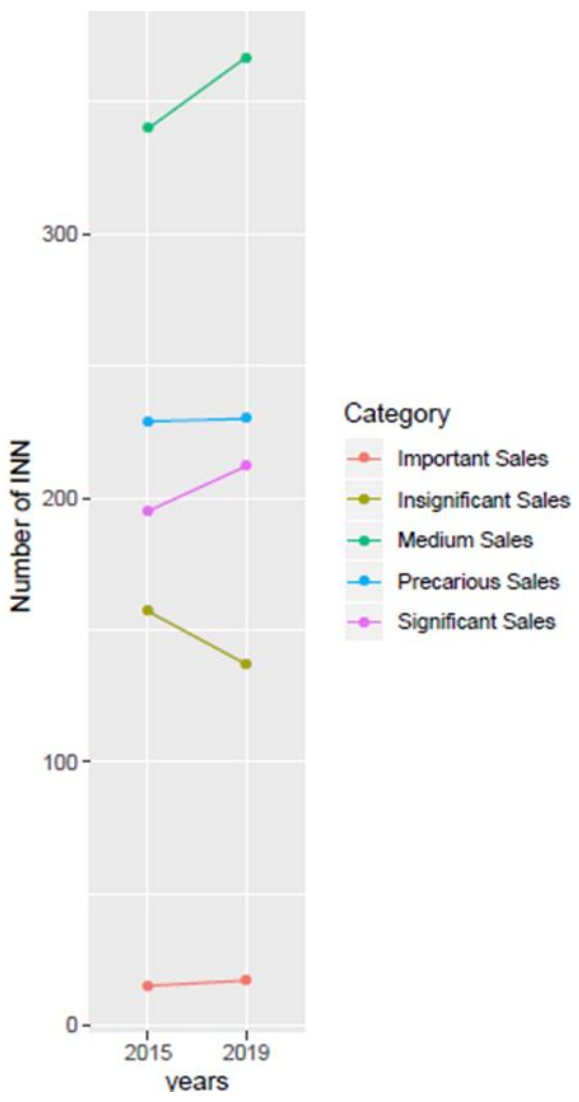

The evolution of the Number of INN and products

The analysis would be more complete if the available data would allow for a detailed breakdown, in terms of patient and disease categories, as well as means of reimbursement. Such analysis remains something desirable for Romania.

The evolution of Rx products in terms of price categories

Analysing the market structure in Romania, of product entries and exits within this period we will try to understand what the outlook is like.

In Figure 5 there can be observed that during July 2014 - June 2015, the Rx drugs with a retail price under 50 RON represent $90.0 \%$ of the volume, a ratio which slightly rises to $91.7 \%$ in the period of July 2018 - June 2019, while the proportion of volume for drugs over 1,000 RON is indiscernible in this graphic. In Figure 6 one can observe that, within July 2014 June 2015, Rx drugs with a retail price under 50 RON represent $45.1 \%$ in terms of value, proportion which drops to $39.5 \%$ during the period of July 2018 June 2019. number of products and the number of INN we can say that it is only significant effect is the type of category $(p<0.001)$. Also, we can say that there is no statistical interaction between the years under research (2015 or 2019) and the other factors under study ( $\mathrm{p}>$ $0.05)$.

Therefore, although they represent the overwhelming majority in terms of volume, the Rx drugs with a retail price of under 50 RON have been affected by the price regulation of 2015 , their weight in terms of value having dropped, moreover the reduced number of this category of products present on the market raises the problem of sustainability of these drugs from an economic point of view; we consider that a weight of at the very least $50 \%$ in terms of value for $90 \%$ of the volume is rational from an economic perspective, in order to avoid a long-term imbalance on the market, which in turn would mean eschewing the minimum price policy.

The price regulation of 2015 was not well targeted, having not addressed in reality the problem of the truly expensive drugs, with a price of over 1,000 RON/ box, which cannot be purchased by large categories of patients unless they are not significantly backed up by the health insurance system. Here too, we have a sustainability problem, this time on behalf of the insurance system, since the weight in terms of the value of these drugs has risen from $16.3 \%$ in July 
2014 - June 2015 to 30,7\% in July 2018 - June 2019. The situation behind these drugs is more complex and addressing it is beyond the scope of this article and the current mechanism of maintaining the budget balance ("claw-back") will only aggravate the issue; we believe that what is needed for this particular segment is a rethinking of the entire regulation system.

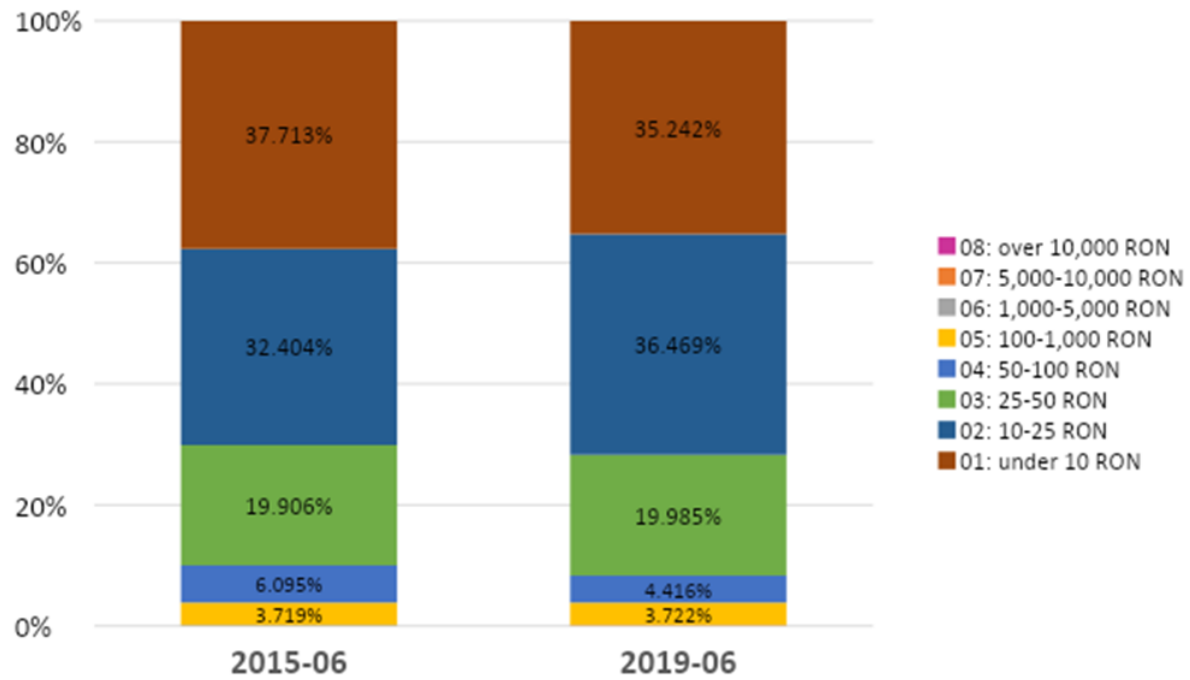

Figure 5.

The Volume of Rx Drugs in terms of Price Categories during the periods July 2014 - June 2015 and July 2018 - June 2019, respectively

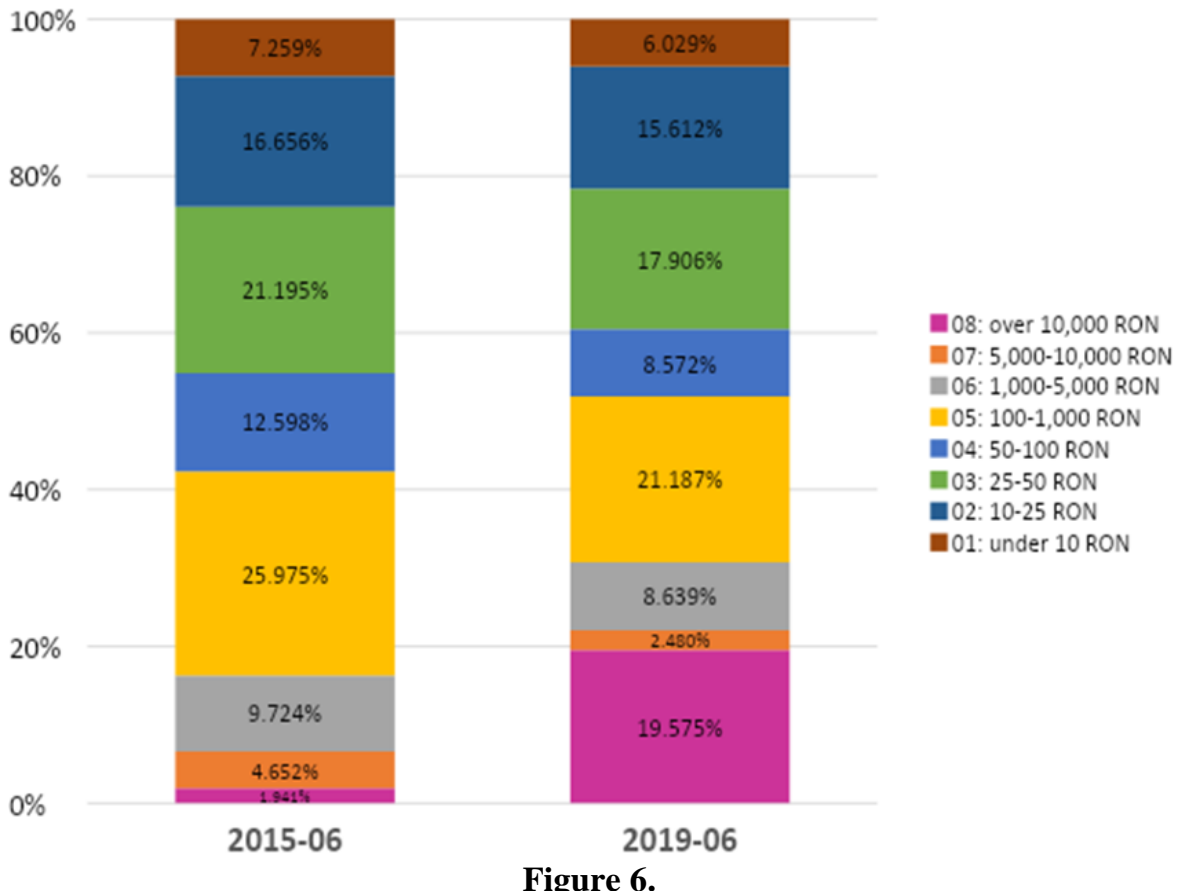

The Value of Rx Drugs by Price Categories during the periods of July 2014 - June 2015 and July 2018 - June 2019, respectively

Up to a point, the market entry of some products and the exit of other products, as well as - on a different scale and with a more reduced frequency - the entry and exit of INNs are normal phenomena, yet that precise point cannot be easily identified. As a consequence, we have considered that what ultimately matter are the end results, beyond opinions, these latter inevitably risking to differ all the time.
In the absence of any cost/benefit analyses, which we consider most useful in the founding of the types of policies such as Rx drugs regulations, we limit ourselves to analysing, within the framework of available data, the following aspects (Table IX): (i) The impact of this regulation in terms of price categories, following the evolution of the total number of products (the difference between the number of products that entered 
FARMACIA, 2021, Vol. 69, 3

the market and the number of those that exited the market in these 4 years); (ii) The variation of value (the difference between the value consumed in July

2018 - June 2019 and that consumed in July 2014 June 2015) in terms of each price category.

Table IX

The Difference between Rx Products that have entered and exited the market and the Value of Rx Products in terms of Price Categories (July 2018 - June 2019 compared to July 2014 - June 2015)

\begin{tabular}{|l|c|c|}
\hline \multirow{2}{*}{ Rx Price Category (CPP) } & $\boldsymbol{\Delta}$ Rx Products on Market & $\boldsymbol{\Delta}$ CPP Value \\
\cline { 2 - 3 } & Items & mil. RON \\
\hline under 10 RON & -94 & 15.12 \\
\hline $10-25$ RON & -135 & -34.94 \\
\hline $25-50$ RON & -108 & 103.03 \\
\hline Subtotal Low Price & $\mathbf{- 3 3 7}$ & $\mathbf{8 3 . 2 0}$ \\
\hline $50-100$ RON & -74 & 84.14 \\
\hline 100-1,000 RON & -47 & 466.91 \\
\hline Subtotal Medium Price & $\mathbf{- 1 2 1}$ & $\mathbf{5 5 1 . 0 6}$ \\
\hline $1,000-5,000$ RON & 62 & 516.83 \\
\hline $5,000-10,000$ RON & 8 & -53.30 \\
\hline over 10,000 RON & 30 & $1,844.58$ \\
\hline Subtotal High Price & $\mathbf{1 0 0}$ & $\mathbf{2 , 3 0 8 . 1 1}$ \\
\hline Total & $\mathbf{- 3 5 8}$ & $\mathbf{2 , 9 4 2 . 3 7}$ \\
\hline
\end{tabular}

One can notice that the number of Rx products has decreased for all the price categories less than 1,000 RON and has increased for all the price categories over 1,000 RON, registering a cumulated difference of over $350 \mathrm{Rx}$ products fewer than in 2015. Likewise, the value for each price category has increased, with the exception of the price ranges of $10-25 \mathrm{RON}$ and that of 5,000 - 10,000 RON, the net result being a plus value of almost 3 billion RON.

In the last years there were implemented many global and national initiatives and regulations in order to improve availability and affordability of medicinal products for human use. The outcome of the reduction of drug prices might be the increasing of users, improving the access to medicines. However, there are many arguments against this measure as investments in innovation might be affected on long-term $[4,7,10]$.

\section{Conclusions}

In Romania, the regulation of prices from July $1^{\text {st }}$ 2015, also known as "the policy of the smallest European price" has produced negative effects, which are somewhat opposed to the initially announced intentions. Although it cannot be made responsible for all aspects, the price policy remains one of the most important leverages available within drug policies, being essential as far as drug availability is concerned and less recommended for drug accessibility, where the key is reimbursement.

The increase in disparities in drug assistance between the large cities and the small towns (including the rural areas), the discrimination of generic drugs, the disappearance of a significant number of products and INNs, the establishment of so-called "in-deficit drugs", as well as the increase of the proportion of truly expensive drugs are all shortcomings of the current price policy and thus recommend the fundamental change of this policy.

As starting points, we believe that a price fixing mechanism in the form of average price for the category of Rx drugs up to $50 \mathrm{RON}$ and the introduction of a QALY type principle for the category of Rx drugs over $1,000 \mathrm{RON}$ represent a feasible approach as far as the actual stage of drug market evolution is concerned and a much more adequate approach for improving the perspectives of drug assistance in Romania.

\section{Conflict of interest}

The authors declare no conflict of interest.

\section{References}

1. Babar ZUD, Pharmaceutical prices in the $21^{\text {st }}$ Century. Springer International Publishing AG, Switzerland, 2015.

2. Birg L, External Reference Pricing and the Choice of Country Baskets and Pricing Rules, 2016, http://dx. doi.org/10.2139/ssrn.2736873.

3. Ess M, Schneeweiss S, Szucs TD, European Healthcare Policies for Controlling Drug Expenditure. Pharmacoeconomics, 2003; 21(2): 89-103.

4. Espin J, Rovira J, Analysis of differences and commonalities in pricing and reimbursement systems in Europe. Brussels: DG Enterprise and Industry of the European Commission, 2007; www.ec.europa.eu/enterprise.

5. European Commission, State of health in the EU: Country profile Romania, 2017.

6. Ghica M, Băncescu I, Udeanu DI, How we deal with small data?. Proceedings of The Romanian National Congress of Pharmacy $-17^{\text {th }}$ Edition, " $21^{\text {st }}$ Century Pharmacy - Between Intelligent Specialization and Social Responsibility”. Filodiritto Editore - Proceedings, 2018; 84-87.

7. Gronde TV, Uyl-de Groot CA, Pieters T, Addressing the challenge of high-priced prescription drugs in the era of precision medicine: A systematic review of drug 
life cycles, therapeutic drug markets and regulatory frameworks. PLoS One, 2017; 12(8): e0182613: 1-34.

8. Kaló Z, Differential Pricing across Europe - Addressing Central-Eastern European Country Needs. Paper presented at the ISPOR $17^{\text {th }}$ Annual European Congress, Amsterdam, 2014.

9. Kawalec P, Tesar T, Vostalova L, Draganic P, Manova M, Savova A, Petrova G, Rugaja Z, Männik A, Sowada C, Stawowczyk E, Harsanyi A, Inotai A, Turcu-Stiolica A, Gulbinovič J, Pilc A, Pharmaceutical Regulation in Central and Eastern European Countries: A Current Review. Front Pharmacol., 2017; 8: 892: 1-16.

10. Levy M, Rizansky Nir A, The pricing of breakthrough drugs: theory and policy implications. PLoS One, 2014; 9(11): e113894: 1-12.

11. Matteucci G, Reverberi P, Drug innovation, price controls, and parallel trade. Int J Health Econ Manag., 2017; 17: 159-179.

12. Moisa C, Vlad AM, Teusdea A, Cadar O, Hoaghia MA, Stan RL, Tăerel A, Jurca C, Vicaș LG, Randomized evaluation on the consumption of antibiotics in community pharmacies. Farmacia, 2018; 66(6): 10811090.

13. Natz A, Heck M, Pharmaceutical Prices: Why are there differences between member states? European Confederation of Pharmaceutical Entrepreneurs AISBL, 2011.

14. Pană M, Crăciun $\mathrm{P}$, Nicolae $\mathrm{C}$, Tăerel $\mathrm{AE}$, Lupuliasa $\mathrm{D}$, The cardiovascular market in Romania during 1998 - 2017 period - analysis and evolution. Farmacia, 2019; 67(5): 922-930.

15. Pauwels K, Simoens S, Casteels M, Huys I, Insights into European Drug Shortages: A Survey of Hospital Pharmacists. PLoS One, 2015; 10(3): e119322: 1-13.

16. $\mathrm{R}$ Core Team. A language and environment for statistical computing. R Foundation for Statistical Computing, Vienna, Austria. 2019, www.R-project.org/.
17. Sehnalova I, Rihova B, Nemecek R, Kintrova K, Demlova $\mathrm{R}$, The real-world cost and effectiveness study of treating mCRC with bevacizumab followed by cetuximab or panitumumab in WT KRAS patients. Farmacia, 2020; 68(3): 572-578.

18. Taerel AE, Rosenberg L, Nicolescu T, Ethics and equity in providing pharmaceutical assistance to the population. Revista Romana de Bioetica, 2010; 8(1): 150-154.

19. Vlãdescu C, Scîntee SG, Olsavszky V, HernándezQuevedo C, Sagan A, Romania: Health system review. Health Syst Transit., 2016; 18(4): 1-170.

20. Vogler S, Habl C, Bogut M, Vončina L, Comparing pharmaceutical pricing and reimbursement policies in Croatia to the European Union Member States. Croat Med J., 2011; 52(2): 183-197.

21. Vogler V, Österle A, Mayer S, Inequalities in medicine use in Central Eastern Europe: an empirical investigation of socioeconomic determinants in eight countries. Int J Equity Health, 2015; 14: 124: 1-19.

22. Vogler S, Zimmermann N, Leopold C, Joncheere $\mathrm{K}$, Pharmaceutical policies in European countries in response to the global financial crisis. South Med Rev., 2011; 4(2): 69-79.

23. von der Schulenburg F, Vandoros S, Kanavos P, The effects of drug market regulation on pharmaceutical prices in Europe: overview and evidence from the market of ACE inhibitors. Health Econ Rev., 2011; 1(1): 18: 1-8.

24. Zaprutko T, Kopciuch D, Kus K, Merks P, Nowicka M, Augustyniak I, Nowakowska E, Affordability of medicines in the European Union. PLoS One, 2017; 12(2): e0172753: 1-13.

25. World Health Organization, WHO guideline on country pharmaceutical pricing policies, 2015.

26. Foundation Note-Government Decision 800/26.10.2016, http://gov.ro.

27. www.cursbnr.ro. 